\title{
Inhibition of allergen-induced airway obstruction and leukotriene generation in atopic asthmatic subjects by the leukotriene biosynthesis inhibitor BAYx 1005
}

\author{
Barbro Dahlén, Maria Kumlin, Elisabeth Ihre, Olle Zetterström, Sven-Erik Dahlén
}

\begin{abstract}
Background - Leukotriene receptor antagonists significantly blunt allergen-induced bronchoconstriction in asthmatic subjects. Inhibitors of leukotriene synthesis should theoretically provide similar protection, but conflicting results have been obtained when synthesis inhibitors have been tested in allergen challenge. BAYx 1005, a new inhibitor of leukotriene synthesis, was therefore evaluated in an allergen bronchoprovocation study. Methods - Ten men with mild allergic asthma and bronchial hyperresponsiveness to histamine were recruited. On two different occasions each subject inhaled a single dose of allergen, previously determined to cause at least a $20 \%$ fall in forced expiratory volume in one second $\left(F E V_{1}\right)$ four hours after ingestion of $750 \mathrm{mg}$ BAYx 1005 or placebo in a double blind crossover design. Urinary excretion of leukotriene $\mathrm{E}_{4}$ was measured before and during the challenges.

Results - The mean (SE) maximal fall in FEV $_{1}$ was $7.1(1.7) \%$ after BAYx 1005 and $21.0(3.0) \%$ after placebo $(p<0.001)$. The mean difference between treatments was $13.9(95 \%$ CI 7.0 to 20.8$)$ for the maximal fall in $\mathrm{FEV}_{1}$. All subjects were protected by BAYx 1005, the mean inhibition of the fall in $F V_{1}$ being 70.0 (7.0)\%. The mean area under the curve (AUC) for urinary excretion of leukotriene $E_{4}$ in the first two hours after the challenge was $1.7(0.9)$ after placebo and $0.4(0.6)$ after BAYx 1005 (difference $=1.3(95 \%$ CI -0.1 to 2.7$)$; p<0.05)

Conclusions - These results indicate that BAYx 1005 is a potent inhibitor of allergenprovoked leukotriene synthesis in asthmatic subjects and lend further support to the suggestion that leukotrienes are important mediators of allergen-induced bronchoconstriction.
\end{abstract}

(Thorax 1997;52:342-347)

Keywords: asthma, BAYx 1005, leukotriene synthesis inhibition, allergens.

Recent experimental and clinical observations suggest that leukotrienes are important mediators of asthma and other inflammatory diseases. ${ }^{12}$ Drugs have therefore been developed to inhibit the action or formation of leukotrienes. Among such antileukotriene drugs, specific receptor antagonists of the cysteinyl leukotrienes $\left(\mathrm{LTC}_{4}, \mathrm{LTD}_{4}\right.$ and $\left.\mathrm{LTE}_{4}\right)$ have been found to inhibit asthmatic reactions induced by allergens, ${ }^{3-6}$ exercise, ${ }^{7-9}$ and aspirin. ${ }^{1011}$

Another class of antileukotriene drugs is represented by compounds which inhibit the biosynthesis of leukotrienes by inhibition of the 5-lipoxygenase or its activation. BAYx 1005 inhibits the production of leukotrienes ${ }^{12}$ by antagonism of the 5-lipoxygenase activating protein (FLAP) $)^{13}$ which has a pivotal role in the stimulation-evoked synthesis of leukotrienes from arachidonic acid. Consistent with this mode of action, BAYx 1005 has been found to inhibit IgE-dependent leukotriene formation in human lung in vitro, as well as the allergeninduced reactions in isolated human bronchi and animal models of asthma. ${ }^{14-16}$

This study evaluates the effect of BAYx 1005 on allergen-induced bronchoconstriction in a group of atopic asthmatic subjects. Furthermore, allergen provocation of asthmatic subjects is associated with release of $\mathrm{LTE}_{4}$ into the urine ${ }^{17-20}$ because a significant proportion of cysteinyl leukotrienes formed in the lungs is excreted by this route, ${ }^{2122}$ so the effect of BAYx 1005 on endogenous formation of leukotrienes was assessed by serial measurements of urinary levels of $\mathrm{LTE}_{4}$.

Despite the current development of antileukotriene drugs for clinical treatment of asthma, a limited number of studies have been published on the effects of different antileukotriene drugs on allergen challenge. In particular, studies on the influence of leukotriene biosynthesis inhibitors on allergic bronchoconstriction are few and have produced variable results. For example, the 5-lipoxygenase inhibitors Zileuton and ZD 2138 failed to cause significant inhibition of allergen-induced bronchoconstriction $^{2324}$ whereas two FLAP antagonists, MK-886 and MK-591, were found to inhibit the response. ${ }^{2526}$

\section{Methods}

PATIENTS

Ten non-smoking atopic men with a history of asthma and with allergy to grass pollen, cat or dog dander participated in the study (table 1). Their asthma was stable and controlled by inhaled $\beta_{2}$ agonists as required. During the study the subjects actively avoided contact with 
Table 1 Subject characteristics

\begin{tabular}{llllll}
\hline Patient no. & Age (years) & $F E V_{1}(\%$ pred) & Histamine $P D_{20}(\mu g)$ & Allergen & Dose $(S Q)^{1}$ \\
\hline 1 & 46 & 76 & 77 & Dog & 71 \\
2 & 24 & 93 & 29 & Grass & 710 \\
3 & 19 & 106 & 220 & Cat & 210 \\
4 & 31 & 100 & 940 & Cat & 781 \\
5 & 29 & 84 & 10 & Dog & 7 \\
6 & 33 & 88 & 60 & Cat & 710 \\
7 & 28 & 79 & 160 & Cat & 213 \\
8 & 23 & 80 & 13 & Dog & 71 \\
9 & 25 & 87 & 415 & Cat & 710 \\
10 & 25 & 97 & 128 & Cat & 923 \\
Mean & 28 & 89 & $88^{2}$ & & \\
Range & $19-46$ & $76-106$ & $10-940$ & & \\
& \\
&
\end{tabular}

the allergens used for provocation. Criteria for inclusion in the study included forced expiratory volume in one second $\left(\mathrm{FEV}_{1}\right)$ of $>75 \%$ predicted and bronchial hyperresponsiveness to histamine, defined as a provocative dose causing a $20 \%$ fall in $\mathrm{FEV}_{1}\left(\mathrm{PD}_{20}\right)$ of $<1210 \mu \mathrm{g}$ measured as previously described. ${ }^{27}$ The study was approved by the local ethics committee and the Swedish Medical Products Agency (Läkemedelsverket). The patients gave informed consent.

STUDY DESIGN

All patients first underwent a screening allergen test to establish their current sensitivity to allergen. The $\mathrm{PD}_{20}$ was determined by linear interpolation from the relation between cumulated dose of inhaled allergen and percentage change in $\mathrm{FEV}_{1}$. Within six months of the screening challenge (mean interval 120 days, range 32-180) the double blind, placebo controlled, crossover drug trial was started. On two separate days the patients received either $750 \mathrm{mg}$ BAYx 1005 or placebo four hours before allergen challenge. Patients reported fasting to the clinic at the same time of the day (07.30 hours) and ingested the tablets under supervision at about 08.00 hours.

Breakfast was given two hours later. The dose of BAYx 1005 used was the highest that had been cleared for human studies at the time the study was performed. The time for preadministration was selected from data on peak plasma concentration (3-5 hours) and plasma half life (3-5 hours) previously determined in pharmacokinetic studies of the compound in man (data on file, Bayer AG, Germany). The compound BAYx $1005^{12}$ was supplied by Bayer AG, Leverkusen, Germany, as $250 \mathrm{mg}$ of a crystalline powder in coated tablets. The two blinded bronchoprovocations were separated by an interval of about four weeks (mean 27 days; range 20-56) and performed by inhalation of the same single dose of allergen on both occasions. The dose used in the blinded provocations (table 1) corresponded roughly to the $\mathrm{PD}_{20}$ value obtained in the screening session.

ALLERGEN PROVOCATION AND STUDY DAY PROCEDURES

Bronchodilators were withheld for eight hours before the allergen challenges and were not used during the study days. Short acting histamine $\mathrm{H}_{1}$ receptor antagonists were not allowed for 48 hours before a study day. Long acting antihistamines, disodium cromoglycate, and non-steroidal anti-inflammatory drugs (NSAIDs) were not used for 10 days before a challenge session. Bronchoprovocation was performed by inhalation of allergen using a dosimeter controlled jet nebuliser (Spira Elektro 2, Respiratory Care Centre, Finland). Driven by compressed air at $7.51 / \mathrm{min}$, the nebuliser generated an aerosol with a mass median particle aerodynamic diameter of $4.1 \mu \mathrm{m}$ and the output was set to $7.1 \mu \mathrm{l}$ per breath. Pulmonary function was measured as $\mathrm{FEV}_{1}$ on a spirometer (Vitalograph MDI Compact, Förbandsmaterial, Sweden). Three concentrations of allergen extract $(1000,10000$, and $100000 \mathrm{SQ} / \mathrm{ml} ; \mathrm{SQ}=$ standardised quality, the manufacturer's unit for allergen strength) were prepared by dissolving lyophilised powder in diluent. The extracts (Aquagen) and the diluent were from ALK Laboratories, Copenhagen, Denmark. By using the three concentrations and by varying the number of breaths from the nebuliser, the protocol used during the screening provocation resulted in approximately half log increments in the cumulated dose of allergen.

Baseline $\mathrm{FEV}_{1}$ was defined as the best of three recordings made five minutes apart. Spirometric values were obtained at hourly intervals after drug administration and the $\mathrm{FEV}_{1}$ value four hours after the drug was used as the baseline value for the ensuing allergen challenge. All challenges were preceded by inhalation of the diluent and, provided $\mathrm{FEV}_{1}$ did not change by more than $10 \%$, bronchoprovocation with allergen was started. Pulmonary function was measured every 15 minutes after inhalation of allergen until the $\mathrm{FEV}_{1}$ had returned to within $10 \%$ of baseline, and thereafter hourly for up to six hours. For monitoring of late asthmatic reactions the patients measured their peak expiratory flow rate (PEFR) with a mini-Wright flow meter hourly after discharge from the hospital and until retiring to bed. The occurrence of a late airway reaction (LAR) was defined as a $20 \%$ drop in PEFR 3-12 hours after the early asthmatic reaction (EAR). The patients returned to the clinic the morning after each treatment day for physical examination, spirometric tests, and sampling of blood.

\section{MEASUREMENTS OF URINARY LTE}

Urine was collected at one hour intervals before drug or placebo, four hours after drug administration, and for up to six hours after the challenge. The samples were divided into different aliquots and stored separately at $-20^{\circ} \mathrm{C}$ and $-70^{\circ} \mathrm{C}$. The concentration of $\mathrm{LTE}_{4}$ was determined with a validated and semi-automated enzyme immunoassay method $^{28}$ and expressed as ng $\mathrm{LTE}_{4} / \mathrm{mmol}$ creatinine.

MEASUREMENTS OF DRUG PLASMA LEVELS

Plasma samples were collected hourly before and after the challenge until the subjects left 


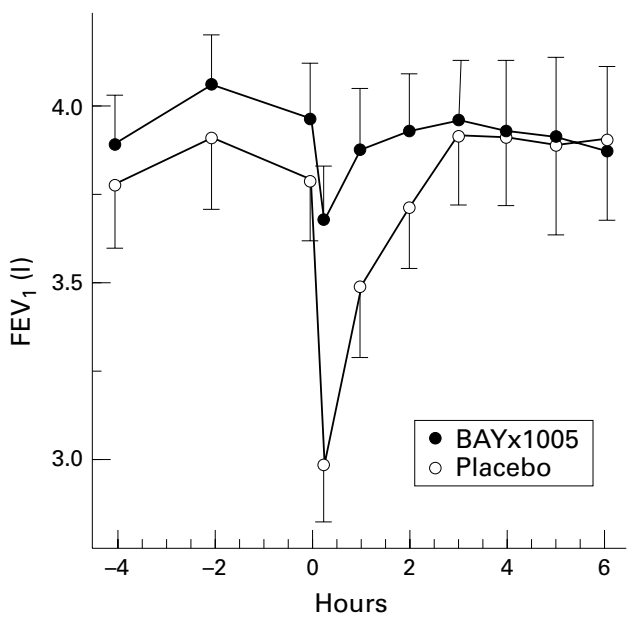

Figure 1 Group mean (SE) values for $F E V_{1}$ on the two study days. Placebo or $750 \mathrm{mg}$ of the leutotriene biosynthesis inhibitor BAYX 1005 were ingested immediately after obtaining the first morning baseline value ( -4 hours). The same single dose of allergen, corresponding to the $P D_{20}$ value determined prior to the study, was inhaled at $t=0$ on both occasions. The peak fall in FEV $V_{1}$ always occurred at the recording taken 15 minutes after the challenge.

the clinic, transported on dry ice, and stored at below $-15^{\circ} \mathrm{C}$ until analysis was performed at the human pharmacokinetic department of Bayer AG in Leverkusen, Germany. The HPLC method had a detection limit of $8 \mu \mathrm{g} / \mathrm{l}$, a precision which varied from $7.6 \%$ to $12.7 \%$, and an accuracy which deviated by a maximum of $3.8 \%$.

ANALYSIS OF DATA

Geometric mean $\mathrm{PD}_{20}$ values were calculated on log transformed raw data. The area under the curves (AUC) for $\mathrm{FEV}_{1}$ versus time and urinary $\mathrm{LTE}_{4}$ versus time were calculated using the trapezoidal rule for integration. Results are presented as means (SE) and mean differences between treatments with $95 \%$ confidence intervals (CI). The data for pulmonary function and urinary levels of $\mathrm{LTE}_{4}$ were found to be normally distributed (SigmaStat software for IBM PC, Jandel Scientific, USA). The Student's paired $t$ test was used to compare group means.

Differences were considered to be significant when the $\mathrm{p}$ value was $<0.05$. Period and carryover effects of the drug treatments were analysed by the method of Hills and Armitage. ${ }^{29}$

\section{Results}

Baseline pulmonary function was not significantly different on the two study days (fig 1 ), nor was there any significant change in $\mathrm{FEV}_{1}$ during the four hours following drug administration (fig 1). There were no subjective or objective signs of drug related side effects after intake of $750 \mathrm{mg} \mathrm{BAYx} 1005$.

There was good agreement between the fall in $\mathrm{FEV}_{1}$ at screening and placebo for the eight subjects who inhaled the same dose of allergen on both occasions with a mean maximal fall of

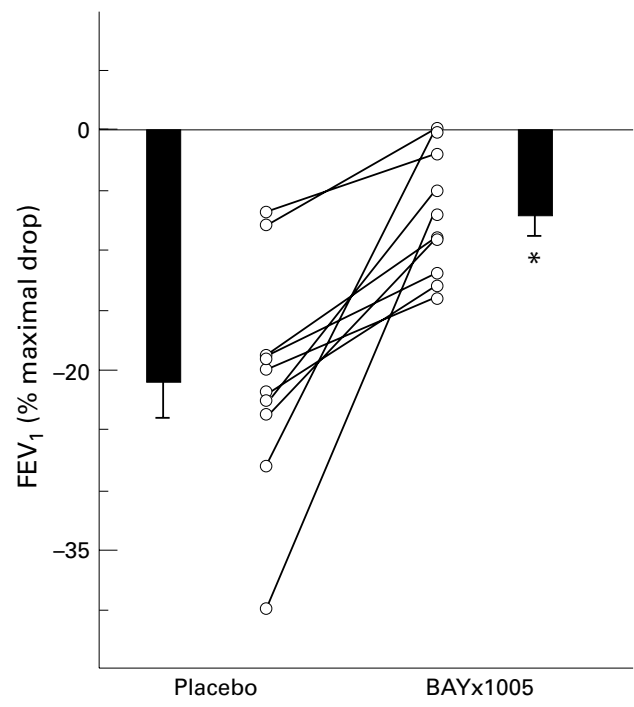

Figure 2 Peak fall in $F E V_{1}$ produced by inhalation of allergen following ingestion of placebo or $750 \mathrm{mg}$ of the leukotriene biosynthesis inhibitor BAYx 1005 four hours before challenge. Individual results ( $\bigcirc$ ) and mean (SE) results for all 10 subjects on each occasion ( $\square$ ) are given. $* p<0.001$, Student's paired t test.

$26.5(2.0) \%$ and $23.5(3.3) \%$ for screening and placebo, respectively. For two subjects ( 4 and 10), the allergen dose selected for use in the double blind sessions (see methods) differed from the dose of allergen inhaled at screening. Subject 1 had late asthmatic reactions on screening and following placebo, but not after BAYx 1005.

The airway response to allergen was substantially inhibited when BAYx 1005 was given prior to challenge, both with respect to the amplitude of the fall in $\mathrm{FEV}_{1}$ and the duration of the reaction (fig 1 ). Figure 2 shows the peak fall for each individual and the group means during the two sessions. The fall in $\mathrm{FEV}_{1}$ was smaller after BAYx 1005 for all subjects. The mean peak fall after placebo was 21.0 (3.0)\% compared with 7.1 (1.7)\% after BAYx 1005. The mean difference between treatments was 13.9 (95\% CI 7.0 to $20.8 ; \mathrm{p}<0.001)$. Thus, the mean inhibition of the fall in $\mathrm{FEV}_{1}$ by BAYx 1005 was 70.0 (7.0)\%. The results were unrelated to the order in which treatments were given.

The mean area under the $\mathrm{FEV}_{1}$-time curve (AUC $\mathrm{FEV}_{1}$ ) during the first hour after challenge was $5.3(0.7)$ and $1.5(0.4)$ for placebo and BAYx 1005, respectively. The mean difference between treatments was 3.8 (95\% CI 2.2 to 5.4$), \mathrm{p}<0.001$, which corresponds to a mean inhibition of the immediate airway response of $74(10) \%$. The inhibition of the response during the first two hours after challenge was similarly calculated to be $63(10.9) \%$.

Group mean baseline values for the urinary excretion of $\mathrm{LTE}_{4}$ did not differ on the two study days (19.5 (6.7) and $23.5(5.6) \mathrm{ng} / \mathrm{mmol}$ creatinine for placebo and drug, respectively), neither were there significant changes in the levels of urinary $\mathrm{LTE}_{4}$ in the time between drug intake and allergen challenge. Thus, at the time of challenge urinary $\mathrm{LTE}_{4}$ levels were 21.5 (4.7) 


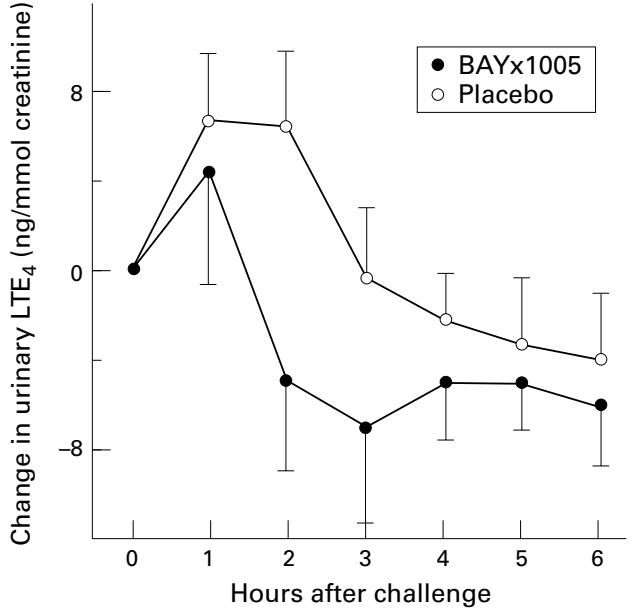

Figure 3 Group mean (SE) changes in post challenge urinary excretion of $\mathrm{LTE}_{4}$ following placebo and the leukotriene biosynthesis inhibitor BAYX 1005. The concentration of $\mathrm{LTE}_{4}$ in the sample of urine collected immediately prior to challenge (four hours after intake of placebo or drug) was selected as the reference on each occasion. For each individual this prechallenge concentration was subtracted from the value in the samples collected every hour after the provocation test. This produced a measure of net excretion after the challenge that was unrelated to each individual's baseline excretion of $\mathrm{LTE}_{4}$.

and $27.6(4.7) \mathrm{ng} / \mathrm{mmol}$ creatinine following placebo and BAYx 1005, respectively.

The net urinary excretion of $\mathrm{LTE}_{4}$ (value after challenge - prechallenge value) was increased after placebo (fig 3). This increase was significantly inhibited during the session when BAYx 1005 had been given. Thus, the mean AUC 0-2 hours after challenge for the net increase in urinary $\mathrm{LTE}_{4}$ was $1.7(0.9)$ for the placebo session and $0.4(0.6)$ for the drug treatment session $(\mathrm{p}<0.05)$, corresponding to an inhibition of $76 \%$. The mean difference between treatments was $1.3(95 \% \mathrm{CI}-0.1$ to 2.7). There were no differences in AUC for urinary $\mathrm{LTE}_{4}$ between drug and placebo at time points later than three hours after challenge. Despite the similar degree of inhibition of urinary $\mathrm{LTE}_{4}$ excretion and bronchoconstriction in the group, there was no correlation between the two responses in individuals $(r=0.20$ for AUC $\mathrm{LTE}_{4}$ at $0-2$ hours versus AUC $\mathrm{FEV}_{1}$ at $0-1$ hours; $p>0.58$ ).

Measurements of drug plasma concentrations confirmed the coding, with no detectable BAYx $1005(<8 \mu \mathrm{g} / \mathrm{l})$ after placebo. On drug treatment days the peak concentration of BAYx 1005 was $10.5 \mathrm{mg} / \mathrm{l}$ (about $30 \mu \mathrm{M}$ ) (range 5.3-19.8 mg/1; SE 2.3) and occurred at $3.5(0.4)$ hours. The mean plasma half life of the drug was found to be $5.2(1.5)$ hours. There was no correlation between the drug levels in the subjects and the degree of inhibition of either the airway response or the urinary excretion of $\mathrm{LTE}_{4}(r<0.5$ for all tested hypotheses).

\section{Discussion}

The leukotriene biosynthesis inhibitor BAYx 1005 significantly inhibited allergen-induced bronchoconstriction. Our findings with BAYx 1005 thus confirm previous indications ${ }^{25}{ }^{26}$ that inhibitors of leukotriene biosynthesis attenuate allergen-induced bronchoconstriction. The inhibition of the early response in this study with BAYx 1005 was superior to that reported for the more short lived leukotriene biosynthesis inhibitor MK-886, ${ }^{25}$ and was identical to that observed with another potent and long lived FLAP antagonist, MK-591. ${ }^{26}$ The leukotriene biosynthesis inhibitors so far reported to protect against allergen-induced bronchoconstriction (MK-886, ${ }^{25} \mathrm{MK}-591,{ }^{26}$ and BAYx 1005) are all FLAP antagonists, whereas the drugs that have failed in allergen challenges of asthmatic subjects $^{2324}$ are directly acting 5-lipoxygenase inhibitors. Studies are required to establish if there is a real difference between the effects of FLAP antagonists and directly acting 5lipoxygenase inhibitors on allergen-induced airway obstruction.

Furthermore, the extent of inhibition (about $70 \%$ ) of the early asthmatic reaction with BAYx 1005 in this study and with MK-591 in the study by Diamant et $a l^{26}$ is similar to the degree of protection which has been observed when allergen challenge has been performed in comparable study protocols after treatment with potent receptor antagonists of cysteinyl leukotrienes. ${ }^{34}$ Likewise, in a parallel study of the effect of BAYx 1005 on allergen-induced bronchoconstriction $^{30}$ a lower dose of BAYx 1005 (500 mg) was given for 3.5 days and caused about $60 \%$ inhibition of the maximal fall in $\mathrm{FEV}_{1}$ during the early response. The similar effects of several structurally unrelated drugs that inhibit the action or formation of leukotrienes by different mechanisms therefore reinforces the suggestion that leukotrienes are major mediators of the early asthmatic response in humans. Secondly, the similar effects of leukotriene biosynthesis inhibitors and receptor antagonists of cysteinyl leukotrienes on the early response to allergen suggests that it is the bronchoconstrictive cysteinyl leukotrienes rather than the leucocyte attractant $\mathrm{LTB}_{4}$ that mediate this particular response.

One of the main end points in this study was to measure $\mathrm{LTE}_{4}$ in urine collected before, during, and after provocation in order to follow the degree of in vivo inhibition produced by BAYx 1005. As expected, ${ }^{19-22}$ the levels of $\mathrm{LTE}_{4}$ were increased in the samples of urine collected within two hours after the placebo treated challenge with allergen. This increase was substantially inhibited by BAYx 1005. The magnitude of inhibition of net release (level after challenge - level before challenge) of $\mathrm{LTE}_{4}$ $(76 \%)$ was similar to the inhibition of the bronchoconstrictor response by the drug (70$74 \%$, depending upon whether the peak fall in $\mathrm{FEV}_{1}$ or AUC at $0-1$ hours was measured). There is therefore good reason to believe that the inhibition by BAYx 1005 of the increase in urinary levels of $\mathrm{LTE}_{4}$ seen after challenge reflected its ability to inhibit pulmonary formation of leukotrienes and consequently the allergen-induced airway obstruction. There was, however, no relation between the drug plasma concentration and the degree of in- 
hibition of bronchoconstriction, nor between drug levels and the extent of inhibition of the allergen-induced urinary excretion of $\mathrm{LTE}_{4}$, supporting previous suggestions that drug plasma levels of leukotriene antagonists or biosynthesis inhibitors do not correlate directly with drug effects on responses caused by the local release of leukotrienes in the airways. ${ }^{52526}$

In contrast to the inhibition of the allergeninduced enhanced urinary excretion of $\mathrm{LTE}_{4}$, the prechallenge levels of urinary $\mathrm{LTE}_{4}$ were unaffected by BAYx 1005. The method of measurement for urinary $\mathrm{LTE}_{4}$ has been thoroughly validated, and the material determined with the present method is highly unlikely to be any other known metabolite of cysteinyl leukotrienes than $\mathrm{LTE}_{4} \cdot{ }^{28}$ The finding therefore indicates that the overflow of urinary $\mathrm{LTE}_{4}$ after allergen challenge reflects pulmonary formation of leukotrienes better than the baseline urinary excretion of $\mathrm{LTE}_{4}$. This is intriguing and cannot be explained, but it may be important to consider in future work on the pharmacology of inhibitors of leukotriene synthesis.

Previous studies of the influence of antileukotrienes on allergen-induced airway obstruction have generated the hypothesis that individuals differ with respect to the participation of leukotrienes, because a proportion of the subjects have been described as nonresponders..$^{3-623}$ In this study, however, all subjects had a smaller and more short lived airway response after BAYx 1005 than after placebo. One reason for this uniform effect could be that the drug was ingested after overnight fasting and was well absorbed, as indicated by homogeneous plasma concentrations around $10 \mu \mathrm{M}$ at the time of the challenge in all subjects. The half life of the drug was found to be 5.2 hours. Together, this indicates effective inhibition of leukotriene synthesis ${ }^{14}$ during the course of the reaction investigated. The findings thus lend strong support to the presence of a leukotriene component in all the subjects studied. The contribution of leukotrienes was most often substantial $(>50 \%$ inhibition for eight of the 10 subjects, $>70 \%$ inhibition for six). Nevertheless, there was some variability in effect (range of inhibition for fall in $\mathrm{FEV}_{1}$ $37-100 \%$ ) which, together with the lack of correlation between individual responses and degree of inhibition of urinary $\mathrm{LTE}_{4}$, may indicate that the relative contribution of leukotrienes and other mediators might vary between individuals.

In conclusion, this study has shown that a single oral dose of the leukotriene biosynthesis inhibitor BAYx 1005 is sufficient to inhibit the early airway reaction to bronchial challenge with allergen. The inhibition was profound (about $70 \%$ of the response) and associated with a similar degree (about $75 \%$ ) of inhibition of post-challenge excretion of urinary $\mathrm{LTE}_{4}$. These findings add to the growing body of evidence in support of leukotrienes as important mediators in asthma, and suggest that this particular leukotriene inhibitor should be studied in other challenge models as well as in the treatment of asthma.
We thank Heléne Blomqvist, Christina Larsson, Lilian Larsson, and Fatima Stensvad for dedicated technical assistance, and D W Langhans of Bayer AG, Germany and Dr Torsten Ryman of Bayer Sweden AB for kind help with practical matter including the assay of plasma levels of BAYx 1005. This study was supported by grants from the Swedish Heart Lung Foundation, the Swedish Association Against Asthma and Allergy, the Swedish Medical Research Council (project 14X-9071), the Swedish Foundation for Health Care Sciences and Allergy Research, and Karolinska Institutet.

1 Dahlén S-E, O'Byrne PM. The eicosanoids: prostaglandins, thromboxane and leukotrienes. In: Pauwels R, O'Byrne thromboxane and leukotrienes. In: Pauwels R, O’Byrne PM, eds. (in press).
(in

2 Chung KF. Leukotriene receptor antagonists and biosynthesis inhibitors: potential breakthrough in asthm therapy. Eur Respir f 1995;8:1203-13.

3 Taylor IK, O'Shaoughnessy KM, Fuller RW, Dollery CT. Effect of cysteinyl-leukotriene receptor antagonist ICI 204, 219 on allergen-induced bronchoconstriction and airway hyperreactivity in atopic subjects. Lancet 1991;337:690-4

4 Rasmussen JB, Eriksson LO, Margolskee DJ, Tagari P, Williams VC, Andersson KE. Leukotriene $\mathrm{D}_{4}$ recepto blockade inhibits the immediate and late bronchoconstrictor responses to inhaled antigen in patients with asthma. F Allergy Clin Immunol 1992;90:193-201.

5 Findlay SR, Barden JM, Easley CB, Glass M. Effect of the oral leukotriene antagonist, ICI 204,219, on antigeninduced bronchoconstriction in subjects with asthma. $\mathcal{f}$ Allergy Clin Immunol 1992;89:104-5.

6 Dahlén B, Björck T, Zetterström O, Dahlén S-E. The leukotriene-antagonist ICI-204,219 inhibits allergen-induced airway obstruction in asthmatics. Eur Respir f 1994; 7:324-31.

7 Manning PJ, Watson RM, Margolskee DJ, Williams VC, Schwartz JI, O'Byrne PM. Inhibition of exercise-induced bronchoconstriction by MK-571: a potent leukotriene D receptor antagonist. $N$ Engl f Med 1990;323:1736-9.

8 Finnerty JP, Wood-Baker R, Thomson H, Holgate ST. Role of leukotrienes in exercise-induced asthma. Inhibitory effect of ICI 204,219, a potent leukotriene $\mathrm{D}_{4}$ receptor antagonist. Am Rev Respir Dis 1992;145:746-9.

9 Robuschi M, Riva E, Fucella LM, Vida E, Barnabe R, Rossi $M$, et al. Prevention of exercise-induced bronchoconstriction by a new leukotriene-antagonist (SK\&F104, 353). Am Rev Respir Dis 1992;145:1285-8.

10 Christie PE, Smith CM, Lee TH. The potent and selective sulfidopeptide leukotriene antagonist, SK\&F 104353, inhibits aspirin-induced asthma. Am Rev Respir Dis 1991; 144:957-8.

11 Dahlén B, Kumlin M, Margolskee DJ, Larsson C, Blomqvist $\mathrm{H}$, Zetterström O, et al. The leukotriene-antagonist MK0679 blocks aspirin-induced airway obstruction induced by bronchial provocation with lysine-aspirin in aspirinby bronchial provocation with lysine-aspirin in aspir
sensitive asthmatics. Eur Respir f 1993;6:1018-26.

12 Hatzelman A, Fruchtmann R, Mohrs KH, Raddatz S, Müller-Peddinghaus R. Mode of action of the new selective leukotriene synthesis inhibitor BAYx 1005 (R) 2 -[4-[quinolin-2-yl-methoxy)phenyl]-2-cyclopentyl acetic acid\} and structurally related compounds. Biochem Phar macol 1993;45:101-11.

13 Dixon RAF, Diehl RE, Opas E, Rands E, Vickers PJ, Evans JF, et al. Requirement of a 5-lipoxygenase-activating protein for leukotriene synthesis. Nature 1990;343:282-4.

14 Gorenne I, Labat C, Gascard JP, Norel X, Müller-Peddinghaus R, Mohrs $\mathrm{KH}$, et al. \{(R)2-[4-[quinolin-2-y]methoxy)phenyl]-2-cyclopentyl acetic acid\} (BAYx 1005), a potent leukotriene synthesis inhibitor: effects on antiIgE challenge in human airways. F Pharmacol Exp Ther IgE challenge in

15 Gardiner PJ, Cuthbert NJ, Francis HP, Fitzgerald MA Thompson AM, Carpenter TG, et al. Inhibition of antigeninduced contraction of guinea-pig airways by a leukotrien synthesis inhibitor, BAYx 1005. Eur f Pharmacol 1994. 258:95-102.

16 Wikström Jonsson E, Dahlén S-E. Interactions between leukotrienes and histamine in the anaphylactic contraction of the guinea pig lung strip. F Pharmacol Exp Ther 1994 271:615-23.

17 Taylor GW, Taylor I, Black P, Maltby NH, Turner N, Fuller $\mathrm{RW}$, et al. Urinary leukotriene $\mathrm{E}_{4}$ after antigen challeng and in acute asthma and allergic rhinitis. Lancet 1989; 5808.

18 Sladek K, Dworski R, Fitzgerald GA, Buitkus KL, Block FJ, Marney Jr SR, et al. Allergen-stimulated release of thromboxane $\mathrm{A}_{2}$ and leukotriene $\mathrm{E}_{4}$ in humans. Am Rev Respir Dis 1990;141:1441-5.

19 Manning PJ, Rokach J, Malo J-L, Ethier D, Cartier A, Girard $\mathrm{Y}$, et al. Urinary leukotriene $\mathrm{E}_{4}$ levels during early and late asthmatic responses. F Allergy Clin Immunol 1990; 86:211-20.

20 Kumlin M, Dahlén B, Björck T, Zetterström O, Granstrom $\mathrm{E}$, Dahlen S-E. Urinary excretion of leukotriene $\mathrm{E}_{4}$ and 11-dehydro-thromboxane $\mathrm{B}_{2}$ in response to bronchial provocations with allergen, aspirin, leukotriene $\mathrm{D}_{4}$ and histamine in asthmatics. Am Rev Respir Dis 1992;146:96-103.

21 Kumlin M, Dahlén S-E. Characteristics of formation and further metabolism of leukotrienes in the chopped human lung. Biochim Biophys Acta 1990;1044:201-10

22 Maltby NH, Taylor GW, Ritter JM, Moore K, Fuller RW, Dollery CT. Leukotriene $\mathrm{C}_{4}$ elimination and metabolism in man. $\mathcal{F}$ Allergy Clin Immunol 1990;85:3-9. 
23 Hui KP, Taylor IK, Taylor GW, Rubin P, Kesterson J, Barnes NC, et al. Effect of a 5-lipoxygenase inhibitor on leukotriene generation and airway responses after allergen challenge in asthmatic patients. Thorax 1991;46:184-9.

24 Nasser SMS, Bell GS, Hawksworth RJ, Spruce KE, MacMillan R, Williams AJ, et al. Effect of the 5-lipoxygenase inhibitor ZD 2138 on allergen-induced early and late asthmatic responses. Thorax 1994;49:743-8.

25 Friedman BS, Bel EH, Tanaka W, Han YHR, Spector R, Sterk P. The effect of a leukotriene biosynthesis inhibitor (MK-886) on allergen-induced bronchoconstriction and in Respir Dis 1993;147:839-44.

26 Diamant Z, Timmers MC, van der Veen H, Friedman BS, De Smet M, Depre M, et al. The effect of MK-0591, a novel 5-lipoxygenase activating protein inhibitor, on a novel 5-lipoxygenase activating protein inhibitor, on
leukotriene biosynthesis and allergen-induced airway re- sponses in asthmatic subjects in vivo. $\mathcal{F}$ Allergy Clin Immuno 1995;95:42-51

27 Nieminen MM, Lahdensuo A, Kellomaeki L, Karvonen J, Muittari A. Methacholine bronchial challenge using dosimeter with controlled tidal breathing. Thorax 1988, 43:896-900.

28 Kumlin M, Stensvad F, Larsson L, Dahlén B, Dahlén S-E. Validation and application of a new simple strategy for measurements of leukotriene $\mathrm{E}_{4}$ in human urine. Clin Exp Allergy 1995;25:467-79.

29 Hills A, Armitage P. The two-period cross-over clinical trial. Br 7 Clin Pharmacol 1979;8:7-20.

30 Hamilton AL, Watson RM, Wyile G, O'Byrne PM. Attenuation of early and late phase allergen-induced bronchoconstriction in asthmatic subjects by a 5-lipoxygenase activating protein antagonist, BAYx 1005. Thorax 1997; 52:348-54 